Check for updates

Cite this: J. Mater. Chem. A, 2020, 8 , 17608

Received 26th April 2020

Accepted 22nd July 2020

DOI: $10.1039 / \mathrm{d} 0 \operatorname{ta} 04406 \mathrm{~g}$

rsc.li/materials-a

\section{Strong reinforcement effects in 2D cellulose nanofibril-graphene oxide (CNF-GO) nanocomposites due to GO-induced CNF ordering $†$}

\author{
Hanieh Mianehrow, (D) a Giada Lo Re, (D) ab Federico Carosio, (iD c Alberto Fina, (D) ${ }^{c}$ \\ Per Tomas Larsson, ${ }^{\text {ad }}$ Pan Chen (D) ae and Lars A. Berglund (D) *a
}

\begin{abstract}
Nanocomposites from native cellulose with low 2D nanoplatelet content are of interest as sustainable materials combining functional and structural performance. Cellulose nanofibril-graphene oxide (CNFGO) nanocomposite films are prepared by a physical mixing-drying method, with a focus on low GO content, the use of very large GO platelets $(2-45 \mu \mathrm{m})$ and nanostructural characterization using synchrotron X-ray source for WAXS and SAXS. These nanocomposites can be used as transparent coatings, strong films or membranes, as gas barriers or in laminated form. CNF nanofibrils with random in-plane orientation, form a continuous non-porous matrix with GO platelets oriented in-plane. GO reinforcement mechanisms in CNF are investigated, and relationships between nanostructure and suspension rheology, mechanical properties, optical transmittance and oxygen barrier properties are investigated as a function of GO content. A much higher modulus reinforcement efficiency is observed than in previous polymer-GO studies. The absolute values for modulus and ultimate strength are as high as $17 \mathrm{GPa}$ and $250 \mathrm{MPa}$ at a GO content as small as 0.07 vol\%. The remarkable reinforcement efficiency is due to improved organization of the CNF matrix; and this GO-induced mechanism is of general interest for nanostructural tailoring of CNF-2D nanoplatelet composites.
\end{abstract}

\section{Introduction}

Polymer nanocomposites based on graphene ${ }^{1-3}$ or other twodimensional platelets ${ }^{4}$ are of great interest, since they can combine load-bearing structural aspects with functionalities required in energy storage, ${ }^{5-8}$ sensors, ${ }^{\mathbf{9}, 10}$ photovoltaics, ${ }^{\mathbf{1 1 , 1 2}}$ organic electronics, ${ }^{13,14}$ biomedical devices ${ }^{15,16}$ etc., but also in membranes, ${ }^{17,18}$ films ${ }^{19,20}$ and coatings. ${ }^{21,22}$ The polymer matrix facilitates processing and shaping; it imparts complex combinations of flexibility, modulus, strength and toughness, and can provide improved chemical stability and gas barrier properties. $^{23-25}$ In order to realize the in-plane mechanical property potential of coatings and films, nanoplatelets need to be

\footnotetext{
${ }^{a}$ Department of Fibre and Polymer Technology, Wallenberg Wood Science Center, KTH Royal Institute of Technology, Teknikringen 56, 10044 Stockholm, Sweden. E-mail: blund@kth.se

${ }^{b}$ Department of Industrial and Materials Science, Chalmers University of Technology, Rännvägen 2, 41296 Gothenburg, Sweden

${ }^{c}$ Dipartimento di Scienza Applicata e Tecnologia, Politecnico di Torino, Alessandria Campus, Via Teresa Michel 5, 15121 Alessandria, Italy

${ }^{d}$ RISE Bioeconomy, Drottning Kristinas Väg 61, SE-11486 Stockholm, Sweden

${ }^{e}$ Beijing Engineering Research Center of Cellulose and its Derivatives, School of Materials Science and Engineering, Beijing Institute of Technology, 5 South Zhongguancun Street, Haidian District, Beijing 100081, China

$\dagger$ Electronic supplementary information (ESI) available. See DOI: 10.1039/d0ta04406g
}

oriented in-plane and well dispersed in the matrix. The need for sustainable materials ${ }^{26}$ adds another criterion to the already challenging design considerations for 2D nanocomposites.

Cellulose nanofibrils (CNF) are sustainable alternatives to other polymers ${ }^{27,28}$ and can form a continuous nanocomposite matrix, e.g. with clay nanoplatelet reinforcements. ${ }^{29,30}$ Wood from forests in Sweden is sustainable in the sense that the annual harvest is lower than the annual growth..$^{31}$ Furthermore, the delignified wood cellulose fibers are classified as sustainable, since modern processes generate more energy than needed for chemical wood cellulose fiber production..$^{32}$ Oxidized $\mathrm{CNF}^{33}$ or native $\mathrm{CNF}$ rich in hemicellulose ${ }^{34,35}$ require very little energy for mechanical disintegration from wood cellulose fibers, and the latter CNF-type can be disintegrated without any extra chemical treatment.

In terms of polymer matrix properties, CNF oriented randomly in-plane can offer higher Young's modulus than other polymers ( $E=15-20 \mathrm{GPa}$ (ref. 36 ) is possible, compared with $E$ = 3-4 GPa for isotropic glassy polymers), and improved stress transfer to $2 \mathrm{D}$ platelets so that the tensile strength of the nanocomposite is improved. Typical wood CNF fibril diameters are $4-10 \mathrm{~nm}$, and lengths $0.7-2 \mu \mathrm{m}$. The effective axial modulus of the CNF fibril is at least $90 \mathrm{GPa},{ }^{37}$ the strength is $1.6-3 \mathrm{GPa} .{ }^{38}$ CNF fibrils can be colloidally stable, ${ }^{39}$ and random in-plane oriented CNF films of 10-100 $\mu \mathrm{m}$ can be readily prepared by filtering and drying in a paper-like process. ${ }^{29}$ After drying, the 
CNF-CNF fibril interaction is very strong due to the mechanisms responsible for paper properties. ${ }^{\mathbf{4 0}}$ An important application of CNF films, is as strong gas barrier layers and coatings replacing synthetic polymers, ${ }^{41}$ and the present CNF nanocomposites could improve the performance of films used in these applications.

CNF hydrocolloids can be readily mixed with e.g. 2D clay platelets ${ }^{29,30}$ or graphene oxide; ${ }^{\mathbf{4 2}}$ so that upon drying, polymer nanocomposites are formed with nanoplatelets dispersed in a CNF matrix. The interest in polymer nanocomposite from $2 \mathrm{D}$ sheets or platelets such as clay, ${ }^{43}$ graphene/graphene oxide, ${ }^{1}$ MXene, ${ }^{44}$ boron nitride ${ }^{45}$ and dichalcogenides such as molybdenum disulfide ${ }^{46}$ is the unique combination of stiffness and strength with specific functionalities. The term platelet is preferred to "sheet", since theoretical models for mechanical properties use "platelet". ${ }^{47}$ In films or coatings, it is essential to have platelet orientation parallel to the surface, since this improves in-plane mechanical, ${ }^{48,49}$ thermal, ${ }^{50,51}$ electrical ${ }^{48,52}$ and gas barrier ${ }^{53-55}$ (out-of-plane) properties. Although layer-bylayer assembly techniques (LBL) can be used to make strong polymer-clay platelet nanocomposite films, ${ }^{56}$ processing is slow and a film-thickness of $4.9 \mu \mathrm{m}$ may require 200 double layers (deposition cycles).

In previous LbL-studies, $\mathrm{CNF}$ is combined with reduced GO (RGO), requiring up to 40 deposition cycles. ${ }^{57}$ Films showed high anisotropic thermal conductivity, but tensile strength was only $107 \mathrm{MPa}$. Liu et al..$^{58}$ made bilayer membranes based on GO and CNF for dye removal from water. The Young's modulus was limited to $4.1 \mathrm{GPa}$ at $4 \mathrm{wt} \%$ GO. Ren et al. ${ }^{59}$ combined LBL and hot pressing to make CNF-GO nanocomposites for low oxygen permeability. By adding $5 \mathrm{wt} \%$ GO, they reported a modulus limited to $4.6 \mathrm{GPa}$. In the present study, a faster filtration approach resembling paper-making is preferred as a processing method, and the film thickness can reach $60 \mu \mathrm{m} .{ }^{29}$ It is critical to be able to control preparation conditions and nanostructural details, since measured nanocomposite properties are typically lower than theoretical predictions.

The present study is focused on sustainable, stiff and strong nanocomposites based on graphene oxide. So far, there are very few experimental studies where polymeric-GO composites really show high absolute values for modulus and strength, ${ }^{60}$ although the theoretical reinforcement efficiency is high. The Young's modulus is estimated to be $200-250 \mathrm{GPa} .{ }^{1}$ GO shows hydrocolloidal stability, ${ }^{61}$ and the functional groups on the GO surface can contribute to improved interface interactions. Polymer nanocomposites can have excellent gas barrier properties $^{62}$ due to the GO platelet geometry. Applications include packaging, ${ }^{63}$ humidity sensors, ${ }^{64}$ coatings for corrosion protection, $^{65}$ materials for metal ion adsorption ${ }^{66}$ and water purification..$^{58,67}$

2D platelets in the form of montmorillonite clay (MTM) were first combined with CNF as a matrix in two studies, ${ }^{29,30}$ with focus on high MTM content. A detailed study of nanostructural effects (orientation, platelet aggregation, nanoporosity) on mechanical properties in CNF-MTM was recently published. ${ }^{68}$ Boron nitride platelets were also combined with CNF, to enhance thermal conductivity. ${ }^{50,69,70}$ For nanocomposites based on cellulosic polymers and GO, the data for mechanical properties are often low, and much lower than theoretical predictions from composite micromechanics. This is true for solvent cast methyl cellulose- $\mathrm{GO}^{71}$ and dissolved and regenerated cellulose-GO. ${ }^{62,72}$ In a recent study on bacterial cellulose nanofibrils/GO, the mechanical property goal was to create a nanocomposite supercapacitor, which could be deformed to small radius of curvature without fracture. ${ }^{73}$

Young's modulus correlates strongly with structural details of a nanocomposite, and is well suited for structure-property studies. It is measured at small deformation, and there are no irreversible changes to the nanostructure, such as plastic yielding or microcracking. High modulus nanocomposites related to $\mathrm{CNF}-\mathrm{GO}$ are typically either based on chemically reduced GO (RGO) or graphene. Yang et al. ${ }^{74}$ used fairly high RGO contents in CNF-RGO (5-50 wt\%), since they investigated electromagnetic shielding and thermal conductivity effects. The reported modulus was below $10 \mathrm{GPa}$. Luong et $a .^{42}$ reported fairly low modulus $(6.4 \mathrm{GPa})$ at an RGO content of $0.3 \mathrm{wt} \%$ in surface-modified CNF, but the strength was improved by RGO. Electrical conductivity was also high due to the graphene-like RGO structure. Laaksonen et al. ${ }^{75}$ investigated sophisticated interface effects in CNF-graphene. The reinforcement efficiency was high and the highest reported modulus was $20 \mathrm{GPa}$ at $1.25 \mathrm{wt} \%$ graphene. Note that graphene is expected to have much higher modulus (1 TPa (ref. 76)) than GO. Dang et al. ${ }^{77}$ At $1 \mathrm{wt} \%$ reinforcement, the $\mathrm{CNF} / \mathrm{GO}$ showed a modulus of $E=4.5 \mathrm{GPa}$ and for graphenelike CNF-RGO data showed $E=9.4 \mathrm{GPa}$. Variations in reported literature data are discussed in the ESI. $\dagger$ The low mechanical properties reported in many studies, must be due to poor organization of the CNF phase, since the present neat CNF film has a modulus of $13.5 \mathrm{GPa}$ and an ultimate strength of $210 \mathrm{MPa}$. Factors such as strong in-plane CNF orientation and reduced void content may have been neglected in a substantial number of previous studies. In the present CNFGO study of nanocomposite films, focus is on low GO content and the use of very large GO platelets $(2-45 \mu \mathrm{m})$, combined with nanostructural characterization using a synchrotron $\mathrm{X}$ ray source for WAXS and SAXS studies. The objective is to better understand GO reinforcement mechanisms in CNF, and to clarify relationships between nanostructure and suspension rheology, mechanical properties, optical transmittance and gas barrier properties. One motivation is that nanocomposites based on polymers and 2D platelets still show properties much inferior to theoretical predictions, possibly because of problems associated with nanostructural control. We report a much higher modulus reinforcement effect than in any other previous CNF-GO or CNF-graphene study. The absolute values for modulus and ultimate strength are as high as $17.3 \mathrm{GPa}$ and $250 \mathrm{MPa}$ at a GO content as small as $0.07 \mathrm{vol} \%$. The remarkable reinforcement efficiency is due to a mechanism not previously discussed or explored, and this opens possibilities for nanostructural tailoring and an increased property range for $\mathrm{CNF}-\mathrm{GO}$, and other CNF-2D nanoplatelet materials. 


\section{Results and discussion}

\section{Characterization of GO platelets}

Large GO platelets should provide efficient reinforcement for in-plane oriented polymer or CNF matrix composites, due to the high aspect ratio. ${ }^{78}$ During tensile deformation, stress is transferred from the matrix to the platelet. For welldistributed platelets, high aspect ratio then means that the reinforcement effect should approach the effect from continuous ribbons of infinite length. For this reason, large GO platelets are synthesized, based on a large initial graphite flake grade and avoiding sonication. The detailed AFM images and lateral size distribution of GO platelets are presented in Fig. S1. $\dagger$ A wrinkled surface structure is observed, which is typical for solution-processed GO. ${ }^{79}$ The lateral size of synthesized GO platelets is mainly in the range $2-45 \mu \mathrm{m}$, although some are smaller than $2 \mu \mathrm{m}$ (Fig. S1c $\dagger$ ). Smaller size platelets are formed by GO cracking during the oxidation process. ${ }^{80}$ The thickness of GO platelets was measured by AFM, and the large majority showed a sheet height of $1.2 \mathrm{~nm}$. This indicates that a large majority of GO platelets are monolayers. ${ }^{\mathbf{8 1 , 8 2}}$ The high aspect ratio is promising with respect to expected reinforcement effects. Size distribution data and height profiles were collected from different samples to ensure they are representative for the whole system.

Raman spectroscopy (Fig. S2 $\dagger$ ) of GO shows the typical extent of defects expected for oxidized graphene. ${ }^{\mathbf{8 3 , 8 4}}$ The degree of oxidation is important, and the carbon to oxygen ratio was 2.27 (Fig. S3 $\dagger$ ), as determined by XPS. IR spectroscopy (Fig. S4 and Table S1 $\dagger$ ) confirm the presence of oxygen functionalities such as carboxyl, hydroxyl and carbonyl groups resulting from the GO preparation process. ${ }^{85}$ Thermal gravimetry data are presented in Fig. S5. $\dagger$

\section{Colloidal stability}

Both TEMPO-CNF and GO are negatively charged, due to the presence of carboxyl groups. The present TEMPO-CNF is from wood and shows a diameter of 2-4 nm and lengths of $0.2-1 \mu \mathrm{m}$ (Fig. S6 $\dagger$ ), with a total charge density as high as $1600 \mu \mathrm{eq} \mathrm{g}^{-1}$. Consequently, electrostatic repulsion occurs between CNF and GO and results in a stable CNF and GO suspension mixture in water (Fig. S7†). This is critical in order to successfully prepare nanocomposites with well-dispersed GO platelets.

The Beer-Lambert law for optical transmittance of nonscattering material can be used to further investigate the dispersion state and stability of the colloidal suspensions. If increased concentration does not lead to sedimentation or nanoparticle aggregation, a linear relationship is expected between the concentration of the suspension and its UV-VIS absorption. ${ }^{86,87}$ GO shows a peak at $235 \mathrm{~nm}$ in UV-VIS, therefore it is possible to track its aggregation using UV-VIS spectroscopy. A suspension of CNF-GO (50:50), was diluted and GO absorption at $235 \mathrm{~nm}$ was recorded at different concentrations. Fig. 1b shows that the suspension of CNF-GO follows the predicted linear Beer-Lambert trend (eqn (1) and (2)), ${ }^{88}$ in support of well-dispersed GO platelets in the colloid.

$$
\begin{gathered}
A=-\log \left(I / I_{0}\right)=\varepsilon c l \\
T=I / I_{0}=\mathrm{e}-{ }^{\varepsilon c l}
\end{gathered}
$$

where $A=$ absorbance, $I_{0}=$ intensity of the incident light, $I=$ intensity of transmitted light, $T=I / I_{0}=$ transmittance, $\varepsilon=$ absorption coefficient, $c=$ concentration of the absorbing species and $l=$ length of the beam in absorbing medium. Since the CNF-GO (50:50) suspension is colloidally stable, other suspensions with lower GO contents, used for composite preparation should be colloidally stable as well.

\section{Optical transmittance}

TEMPO oxidized CNF has a diameter of 2-4 nm and corresponding thin nanopaper films with random-in-the-plane CNF orientation have been reported to show high optical transmittance and low haze, meaning low fraction of transmitted light scattered at wide angles. ${ }^{89}$ Images of the TEMPO-CNF nanopaper and CNF-GO nanopaper films are presented in Fig. 1c. The light absorbance of GO substantially reduces optical transmittance. ${ }^{90}$ The quantification of changes in optical transmittance of CNF-GO with GO content is presented in Fig. 1d. The addition of $0.07 \mathrm{vol} \%$ GO only reduces the optical transmittance from $94 \%$ for neat CNF to $90 \%$ (at $550 \mathrm{~nm}$ ). Since this amount of added GO is very low, the transmittance is high and films may have potential as transparent coatings in packaging. ${ }^{41}$ The optical transmittance decreases with increased GO content and is $23 \%$ for CNF-GO nanopaper with $2.7 \mathrm{vol} \% \mathrm{GO}$ (CNF-GO 2.7). Haze values vary from $4.5 \%$ for neat CNF to $6.5 \%$ for CNF-GO 2.7. These data show that GO has very little influence on the light scattering of nanocomposite films. The optical transmittance of CNF-GO films at $550 \mathrm{~nm}$ decreases exponentially with higher GO content by adding more GO (Fig. S8†) which is in agreement with the Beer-Lambert model (eqn (2)). The absorption coefficient $(\varepsilon)$ of CNF-GO films is calculated to be $160 \mathrm{~cm}^{-1}$ by fitting the model to experimental data (Fig. S8 $\dagger$ ). Since the absorption coefficient is known, the optical transmittance of CNF-GO films at other GO contents can be predicted.

\section{Rheology of CNF-GO gels}

The degree of GO dispersion in high concentration colloidal CNF-GO gels is used to estimate "miscibility" of CNF and GO. Aggregation in the colloidal state is detrimental to mechanical reinforcement effects and optical transmittance in solid nanocomposite films, since aggregates will persist during solidification and reduce the nanoparticle dispersion state. The rheological shear behavior was therefore investigated for CNF and CNF-GO gels. The nanoparticle concentration was constant in the hydrocolloidal gels ( $0.6 \mathrm{wt} \%$ solid), and the relative CNFGO composition of solid phase was the same as in as-prepared CNF-GO nanopaper films $(0,0.07,0.3,0.7,1.3$ and 2.7 vol\% of GO).

In Fig. 2, all CNF-GO suspensions show higher complex viscosity than neat CNF (Fig. 2a). GO addition strongly increases complex viscosity and storage modulus for CNF-GO gels at 
(a)

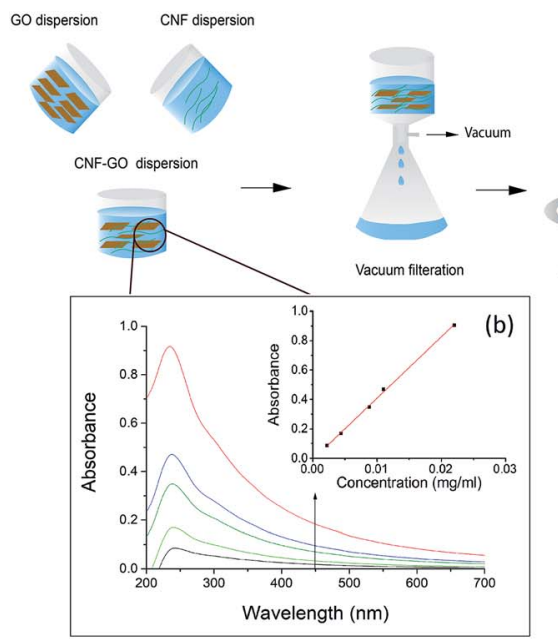

(c)
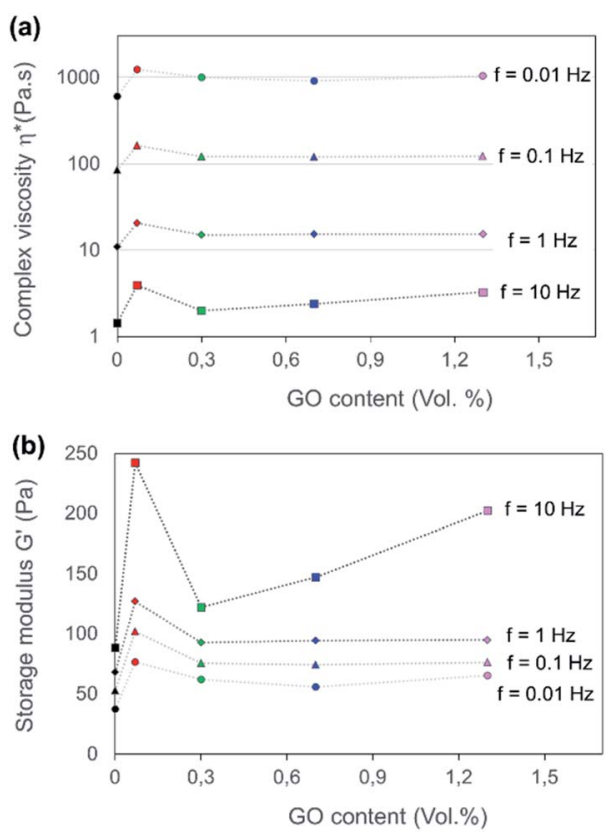

Fig. 2 Frequency sweep results of complex viscosity during dynamic experiments (a) and shear storage modulus (b) of CNF and CNF-GO colloidal gels as a function of GO content. The solid content of the colloid is the same for all compositions at $0.7 \mathrm{wt} \%$, and the fraction of $\mathrm{GO}$ in the solid is $0.07-1.3$ vol\%, which is the same composition as in the CNF-GO films.

small strain, due to the large aspect ratio of GO platelets. Interestingly, this effect is the largest at the lowest GO content $(\mathrm{GO}=0.07 \mathrm{vol} \%$ ), see Fig. 2, indicating that the dispersion of GO is much better at lower contents. At higher GO content, complex viscosity and, in particular, storage modulus are decreased, due to aggregation of GO platelets. This effect is more pronounced for storage modulus at higher frequencies
(Fig. 2b). An important reason for aggregation is the very large aspect ratio of the present GO platelets. For geometrical reasons, even at low concentration, they cannot be randomly distributed in space without interacting with each other. As a clarification, a colloid with well-dispersed particles would have shown continuous increase in complex viscosity and storage modulus with particle content.

All CNF-GO gel compositions showed shear-thinning behavior in terms of complex viscosity, with a similar slope of $\omega>0.628 \mathrm{rad} \mathrm{s}^{-1}(f>0.1)$. This is consistent with the theoretically expected behavior of rod-like fibril suspensions. ${ }^{91,92}$ The geometry of the CNF nanofibrils and their flexibility results in progressive partial orientation and disentanglement of fibrils under shear, so that viscosity decreases with increasing shear rates (proportional to the frequency f). ${ }^{93} \mathrm{GO}$ may also contribute to shear-thinning by reorientation in the flow field. Based on rheological results in Fig. 2, CNF-GO 0.07 shows the best dispersion state of the GO. The effect on storage modulus $G^{\prime}$ at $10 \mathrm{~Hz}$ is the strongest, and this experiment is thus highly sensitive to aggregation effects.

\section{Mechanical properties of CNF-GO nanopaper films}

The mechanical properties of the CNF-GO nanopaper are presented in Fig. 3 and Table 1. An unexpectedly strong reinforcement effect from GO addition is observed for mechanical properties at a GO content of only 0.07 vol\% $(0.1 \mathrm{wt} \%)$. The stress-strain curve shows strongly increased yield stress at only 0.07 vol\% GO and steeper strain hardening beyond the yield point. The ultimate strength is increased but the increase in Young's modulus is remarkable, see Fig. 3b. The modulus of CNF-GO 0.07 reaches a value as high as $17.5 \mathrm{GPa}$, whereas the neat $\mathrm{CNF}$ reference material has a modulus of $13.5 \mathrm{GPa}$. The modulus increase is strongest for the 0.07 vol\% GO composition. When the GO content is increased more than 4 times (from $0.07 \mathrm{vol} \%$ to $0.3 \mathrm{vol} \%$ ), the increase in modulus is only from 


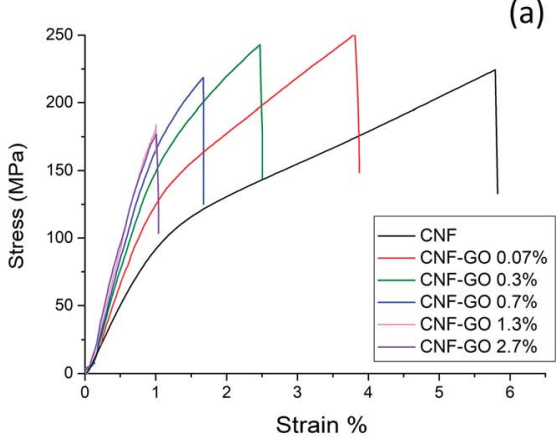

(c)

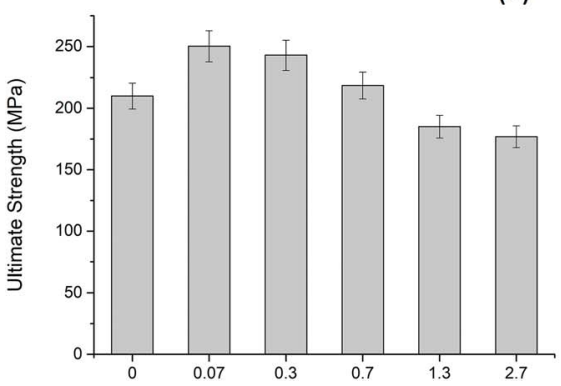

(b)

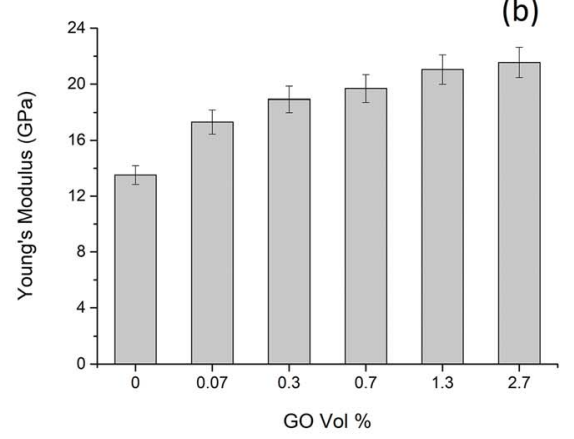

(d)

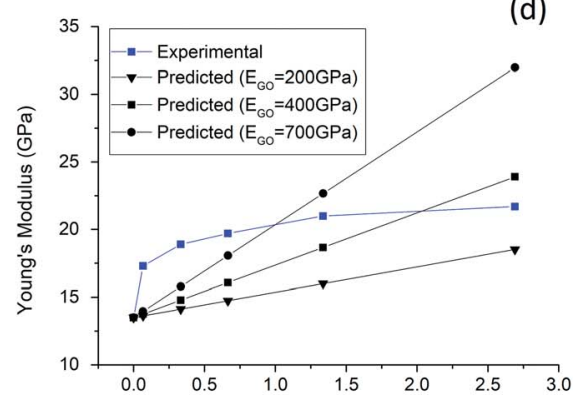

Fig. 3 Representative stress-strain curves of CNF-GO nanopaper films (a) Young's modulus (b) and ultimate strength (c) as a function of GO content. (d) Shows experimental Young's modulus of CNF-GO films versus GO content. Predicted modulus data are calculated from eqn (3) (rule of mixtures) assuming three different and very high values for $\mathrm{GO}$ modulus, the CNF phase is assumed to have a modulus $E_{2}=13.5 \mathrm{GPa}$, based on the present experimental data for CNF films.

17.3 to $18.9 \mathrm{GPa}$. It means the reinforcement efficiency is lower for the $0.3 \mathrm{vol} \%$ composition. At a GO content of $0.3 \mathrm{vol} \%$, the ultimate strength is lower than for 0.07 vol\% GO (Fig. 3c). This suggests significant GO aggregation at higher GO content, as supported by the rheology results. Strain to failure is also reduced as the GO content is increased.

Previous mechanical property data for comparable nanocomposites are presented in Table 2 . The present data with only $0.1 \mathrm{wt} \%(0.07 \mathrm{vol} \%)$ of GO represent by far the strongest reinforcement effect, since properties are comparable with $\mathrm{CNF}$ / graphene nanocomposites of $1.2 \mathrm{wt} \%$ graphene content. ${ }^{75}$ Since graphene has much higher elastic modulus than GO, it is possible that graphene aggregation reduces properties in ref. 94. The ultimate strength for the 0.07 vol\% composition is increased from $210 \mathrm{MPa}$ for neat CNF to reach $250 \mathrm{MPa}$, which is significantly higher than for a previous CNF/GO study (110 wt\% GO), ${ }^{77}$ but slightly lower than for CNF/graphene. ${ }^{42,75}$ The best strength values for $\mathrm{CNF} /$ graphene are reported in ref. 94 . The present observation of strong reinforcement effects at very low GO content requires further analysis, in particular with respect to the mechanism behind the strongly enhanced Young's modulus. It is apparent that a large majority of previous studies have not paid sufficient attention to the structural organization of the CNF matrix, so that modulus data for nanocomposites are even below $10 \mathrm{GPa}$, see Table 2. The table is discussed in detail in the ESI. $\dagger$

In order to clarify the CNF-GO Young's modulus reinforcement mechanism, the rule of mixtures (eqn (3)) for in-plane oriented platelets of high aspect ratio in continuous matrix is used $^{47}$ and compared with data in Table 1.

$$
E_{\mathrm{C}}=E_{1} V_{1}+E_{2} V_{2}+\frac{V_{1} V_{2} E_{1} E_{2}\left(\nu_{1}-\nu_{2}\right)^{2}}{E_{1} V_{1}\left(1-\nu_{1}^{2}\right)+E_{2} V_{2}\left(1-\nu_{2}^{2}\right)}
$$

Table 1 Summary of mechanical properties of CNF-GO films, conversion from weight fraction to volume fraction is made assuming nonporous films, see ESI

\begin{tabular}{|c|c|c|c|c|c|c|}
\hline Sample & $\begin{array}{l}\text { Volume fraction } \\
\text { of GO }(\%)\end{array}$ & Density $\left(\mathrm{g} \mathrm{cm}^{-3}\right)$ & $\begin{array}{l}\text { Young's modulus } \\
\left(E_{\mathrm{C}}\right)(\mathrm{GPa})\end{array}$ & $\begin{array}{l}\text { Yield strength } \\
\left(\sigma_{\mathrm{y}}\right) \\
(\mathrm{MPa})\end{array}$ & Ultimate strength $\left(\sigma_{\mathrm{C}}^{*}\right)(\mathrm{MPa})$ & Strain to failure $\left(\varepsilon_{\mathrm{C}}^{*}\right)(\%)$ \\
\hline $\mathrm{CNF}$ & 0 & $1.5 \pm 0.1$ & $13.5 \pm 0.7$ & $93.3 \pm 5.2$ & $210.1 \pm 10.5$ & $5.2 \pm 0.3$ \\
\hline CNF-GO 0.1\% & 0.07 & $1.5 \pm 0.1$ & $17.3 \pm 0.8$ & $127.8 \pm 4.7$ & $250.3 \pm 12.5$ & $4.8 \pm 0.2$ \\
\hline CNF-GO 0.5\% & 0.3 & $1.5 \pm 0.1$ & $18.9 \pm 0.9$ & $141.8 \pm 4.5$ & $243.5 \pm 12.1$ & $3.3 \pm 0.2$ \\
\hline CNF-GO 1\% & 0.7 & $1.6 \pm 0.1$ & $19.7 \pm 0.9$ & $152.5 \pm 3.7$ & $218.6 \pm 10.9$ & $2.3 \pm 0.1$ \\
\hline CNF-GO $2 \%$ & 1.3 & $1.6 \pm 0.1$ & $21.0 \pm 1.0$ & $169.8 \pm 2.0$ & $185.1 \pm 9.2$ & $1.6 \pm 0.1$ \\
\hline CNF-GO $4 \%$ & 2.7 & $1.6 \pm 0.1$ & $21.5 \pm 1.0$ & $165.8 \pm 2.3$ & $176.9 \pm 8.8$ & $1.3 \pm 0.1$ \\
\hline
\end{tabular}


Table 2 Comparison between the mechanical properties of the present CNF-GO nanocomposite and literature data ${ }^{a}$

\begin{tabular}{|c|c|c|c|c|c|c|c|}
\hline \multirow[b]{2}{*}{ Sample } & \multirow[b]{2}{*}{$\begin{array}{l}\text { Platelet } \\
\text { content (wt } \%)\end{array}$} & \multicolumn{2}{|l|}{ Matrix } & \multicolumn{2}{|l|}{ Composite } & \multirow[b]{2}{*}{$\begin{array}{l}\text { Preparation } \\
\text { method }\end{array}$} & \multirow[b]{2}{*}{ Year } \\
\hline & & $\begin{array}{l}\text { Young's } \\
\text { modulus (GPa) }\end{array}$ & $\begin{array}{l}\text { Ultimate strength } \\
\text { (MPa) }\end{array}$ & $\begin{array}{l}\text { Young's } \\
\text { modulus (GPa) }\end{array}$ & $\begin{array}{l}\text { Ultimate } \\
\text { strength } \\
(\mathrm{MPa})\end{array}$ & & \\
\hline \multirow[t]{2}{*}{ CNF-GNS-P } & 1.25 & $\sim 9.0$ & $\sim 110$ & 20.2 & 278 & Vacuum filtration & 2011 (ref. 75) \\
\hline & 0.5 & & & 18.0 & 220 & & \\
\hline & 5 & & & 7.1 & 273 & & \\
\hline \multirow[t]{2}{*}{ CNF-GNS } & 0.62 & 11.2 & $\sim 290$ & 12.0 & 260 & Vacuum filtration & 2012 (ref. 94) \\
\hline & 1.25 & & & 16.9 & 351 & & \\
\hline CNF-RGO & & & 153 & - & 136 & LBL (20 bilayers) & 2013 (ref. 95) \\
\hline \multirow[t]{2}{*}{ CNF-GO } & 4.4 & 3.8 & 92.9 & 4.6 & 140.9 & Vacuum filtration & 2015 (ref. 96) \\
\hline & 8.45 & & & 4.8 & 73.3 & & \\
\hline CNF-RGO- & 95 & - & 200 & - & 314.6 & Solvent casting & 2016 (ref. 98) \\
\hline \multicolumn{8}{|l|}{ PCDO } \\
\hline CNF-RGO & 30 & - & 117 & - & 90 & Vacuum filtration & 2016 (ref. 99) \\
\hline \multirow[t]{2}{*}{ TCNF-RGO } & 20 & 6.3 & 189.4 & 7.04 & 98.1 & Vacuum filtration & 2017 (ref. 74) \\
\hline & 50 & & & 7.7 & 67.7 & & \\
\hline CNF-RGO & 10 & - & 142 & - & 107.0 & LBL (40 bilayers) & 2017 (ref. 57) \\
\hline CNF-GNS & 30 & 6.04 & 181.3 & 7.4 & 140.3 & Vacuum filtration & 2017 (ref. 100) \\
\hline CNF-GNS & 10 & 5.9 & 94.52 & 6.2 & 116.8 & Vacuum filtration & 2017 (ref. 101) \\
\hline CNF-GO & 5 & 0.08 & 29.1 & 4.5 & 62.3 & LBL (10 bilayers) & 2019 (ref. 59) \\
\hline TCNF-GO & 4 & $\sim 3.0$ & 50.2 & 4.1 & 80.0 & LBL (a bilayer) & 2019 (ref. 58) \\
\hline CNF-GNS & 10 & - & 81.9 & - & 89.9 & Vacuum filtration & 2020 (ref. 102) \\
\hline CNF-GNS-PDA & & & & & 102.8 & & \\
\hline
\end{tabular}

$E_{1}$ and $E_{2}$ are defined as Young's modulus of CNF and GO respectively, $V_{1}$ and $V_{2}$ are their volume fractions and $\nu_{1}$ and $\nu_{2}$ are Poisson's ratio of each of them. By consideration of literature data for Poisson's ratio for $\mathrm{CNF}^{\mathbf{1 0 3}}$ and for $\mathrm{GO},{ }^{\mathbf{1 0 4}}$ the last term of eqn (3) becomes negligible.

Comparison between $E_{\mathrm{C}}$ values predicted based on Young's modulus of CNF network (13.5 GPa) and several values for Young's modulus of GO are presented in Fig. 3d. Three different values are used for the modulus of GO (200, 400 and $700 \mathrm{GPa})$ based on data in the literature. ${ }^{\mathbf{1 0 5 - 1 0 7}}$ Predicted $E_{\mathrm{C}}$ is much lower than experimental data for the three lowest weight fractions of GO. Even when $E_{\mathrm{GO}}$ is assumed to be $700 \mathrm{GPa}$, the experimental data are much higher than predictions. Since the model is based on an assumption of perfect adhesion between the reinforcing platelet and the CNF "matrix", interfacial adhesion effects cannot explain the strong reinforcement results in Fig. 3d for the lowest GO content.

One hypothesis is that in CNF-GO nanocomposites, the effective Young's modulus of the CNF matrix is higher than the measured 13.5 GPa due to lower stress relaxation effects from the presence of GO platelets. During a quasi-static tensile test of the present materials, there may be stress-relaxation effects which reduce the short-term Young's modulus. Stress relaxation tests were therefore performed and CNF nanopaper data are presented in Fig. S9. $\uparrow$ The time scale to obtain small strain modulus data is less than 10 seconds, and during that time the data for neat CNF nanopaper in Fig. S9† show that stress relaxation effects are negligible and cannot explain the reinforcement effect in Fig. 3. In order to exclude this possibility, stress relaxation was also characterized for the CNF-GO composites, and effects are very weak, see Fig. S9. $\dagger$

Counter ions can have strong effect on stress-strain curves of CNF nanopaper. ${ }^{108}$ To investigate if the counter ions in the initial suspension of GO could explain the strong reinforcement effect, XPS of GO was performed (Fig. S3 $\dagger$ ). Results showed that the amount of residual counterions in the GO suspension, after washing, was very small. Effects from variations in the amount of counterions are therefore expected to be negligible.

The remaining hypothesis is that ordering of the CNF matrix is improved by the presence of GO platelets. The effective matrix modulus in Fig. 3b is then improved in the composite, compared with the modulus for the neat CNF nanopaper. In the famous study by Toyota researchers, ${ }^{109}$ PA6-nanoclay composites were prepared by injection molding. The mechanical property improvement compared with neat PA6 was dramatic. One important reason was that PA6 properties were better in the 
composite than in neat PA6, because of strong PA6 molecular orientation effect and higher crystallinity. Similar matrix effects have been discussed for polylactide-cellulose ${ }^{\mathbf{1 1 0}}$ nanocomposites, and cellulose triacetate-cellulose nanocomposites. ${ }^{\mathbf{1 1 1}}$

Zhao et al. ${ }^{112}$ reported that casting and slow solidification of CNF nanopaper films resulted in much better mechanical properties than for filtered nanopapers. The reason was that slow nanopaper formation promoted nematically ordered domains of CNF fibrils. Based on this observation, the strong reinforcement effect in $\mathrm{CNF}-\mathrm{GO}$ nanopaper might be related to higher degree of ordering in the CNF network in the presence of GO. To investigate this hypothesis, morphological analysis was carried out followed by small angle scattering measurements to obtain nanoscale level data on supramolecular ordering.

The cross-sections of neat CNF and CNF-GO 0.07 nanopaper films after tensile tests (fracture surfaces) are presented in Fig. $4 \mathrm{a}, \mathrm{b}$, e and f. Both samples appear homogeneous and no large GO aggregates are apparent, in support of rheology data. Smaller aggregates of GO are expected to be thin, and not observable at the scale of magnification in Fig. 4; and the problem has been discussed previously. ${ }^{\mathbf{9 6}}$ The nanostructure of CNF-GO 0.07, however, shows fibrous structures on a larger scale in comparison with neat CNF nanopaper. Fibrillar structures simply have larger diameter in the CNF-GO 0.07 composition.

Nanostructural changes in CNF-GO nanopaper were investigated by Small Angle X-ray Scattering (SAXS) and Wide Angle $\mathrm{X}$-ray Scattering (WAXS) techniques, where the X-ray beam was parallel or perpendicular to the film plane. When the beam is perpendicular to the film plane (Fig. S10†), no preferred orientation is observed for the nanopaper and CNFs show random orientation in the film plane. For the CNF-GO 0.07 nanopaper, the intensity is much stronger than for the neat CNF film, in the equatorial direction. This is in qualitative support of a stronger in-plane orientation of CNF in the CNF-GO 0.07 nanopaper.

More details are revealed based on SAXS patterns (Fig. 4c and $\mathrm{g})$, where a narrow streak is apparent, a consequence of strong CNF orientation in the direction parallel to the film surface. The WAXS gives information about the orientation at the scale of crystal lattice (length scale up to about $1 \mathrm{~nm}$ ), whereas SAXS is probing larger length scales (ranging from a few $\mathrm{nm}$ to several hundred nm depending on the selected $q$ range). The azimuthal distribution extracted from SAXS and WAXS data (Fig. 5) is used to quantify the orientation of CNFs in the presence of GO at different length scales. The degree of orientation (П) and Herman's orientation factor $(f)$ are calculated and shown in Table 3 (see $\mathrm{ESI} \dagger$ for calculation procedure). Results show that by adding GO to CNF, even as little as 0.07 vol\%, the degree of in-plane orientation of CNF increases strongly from 0.82 to 0.92 at $q=$ $0.6-0.9 \mathrm{~nm}^{-1}$ and from 0.76 to 0.86 at $q=1-2 \mathrm{~nm}^{-1}$ and from 0.79 to 0.82 at $q=15-18 \mathrm{~nm}^{-1}$. In the $q=15-18 \mathrm{~nm}^{-1}$ range, the accuracy of orientation data is lowered, since the number of pixels for WAXS detection is limited. However, a comparison can be made between CNF films with and without GO. The data show that the orientation of CNF phase is increased in the presence of GO at multiple length scales (from 0.4 to $60 \mathrm{~nm}$ ). The effective Young's modulus of the continuous CNF matrix phase in the composite is then increased compared with neat CNF film data. This observation is critical for explanation of the strong reinforcement effect.

In Fig. 6, SAXS data are plotted for CNF-GO 0.07 and the references neat $\mathrm{CNF}$ and neat GO films, where the X-ray beam is perpendicular to the film plane. In the low $q$-range (0.1-0.3 $\mathrm{nm}^{-1}$ ) the CNF sample shows a higher intensity than the CNF-
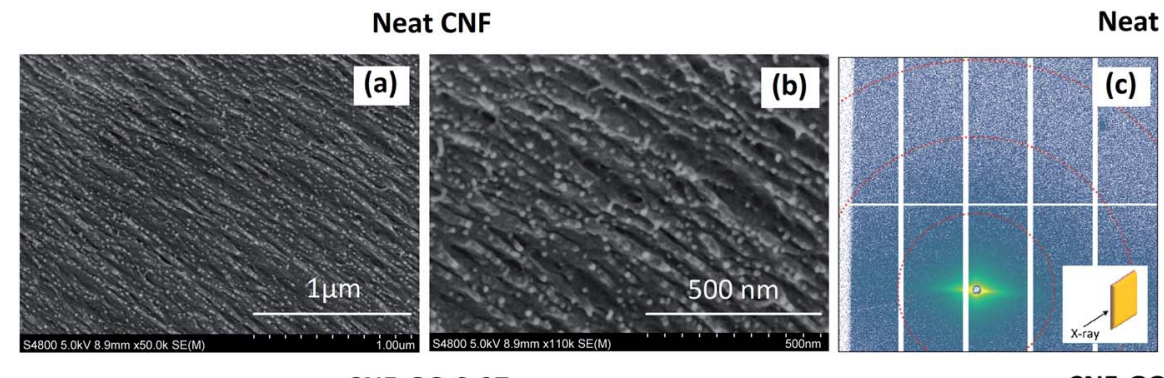

Neat CNF

CNF-GO 0.07

CNF-GO 0.07
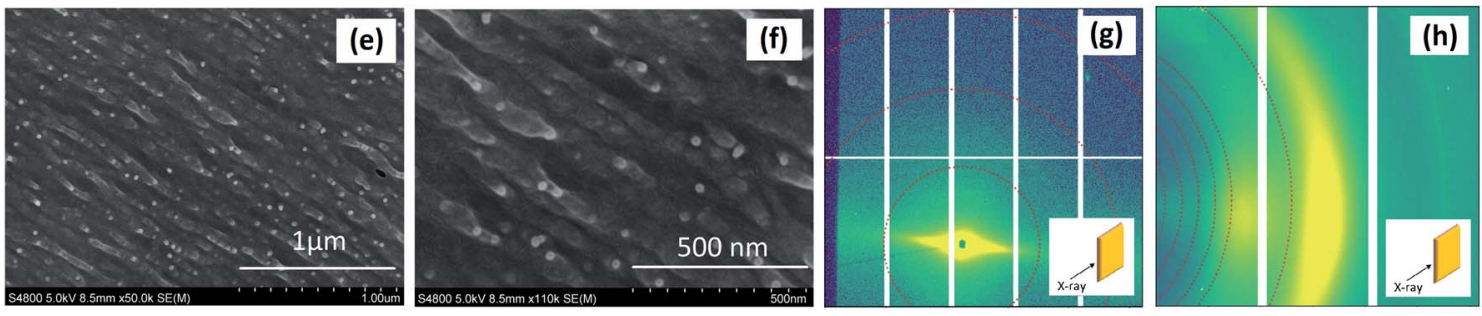

Fig. 4 FE-SEM images of fractured cross-sections of CNF ( $a$ and b) after tensile tests with two different magnifications. Corresponding SAXS (c) and WAXS (d) diffraction patterns are presented, where the X-ray beam is parallel to the film plane. FE-SEM images of CNF-GO 0.07 nanopaper (e and f) and corresponding SAXS (g) and WAXS data (h). Note that the plane parallel to the surface is parallel to diagonal direction of the films in $a, b$, e, f. 

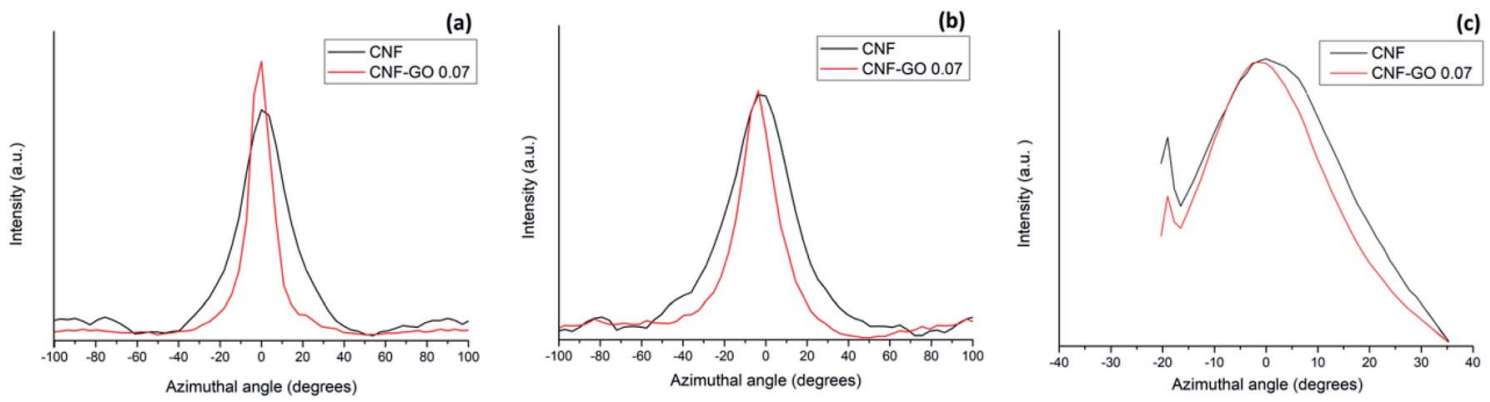

Fig. 5 Azimuthal angle distribution of CNF and CNF-GO 0.07 at three different q ranges. (a) $q=0.6-0.9 \mathrm{~nm}^{-1}$, (b) $q=1-2 \mathrm{~nm}^{-1}$ and (c) $q=15-$ $18 \mathrm{~nm}^{-1}$.

GO 0.07 composite. The interpretation is that this is not an effect from GO itself since the intensity does not scale with GO content. Compared with the CNF sample, the CNF-GO 0.07 sample gives a larger intensity over the $q$-range 0.4 to $0.1 \mathrm{~nm}^{-1}$. This is interpreted as a larger abundance of electron density periodicities in the CNF-GO 0.07 sample. This can be due to increased in-plane ordering, as observed in the scattering measurements performed with the beam parallel to the film plane. At a $q$-value of $0.1 \mathrm{~nm}^{-1}$ which corresponds to $60 \mathrm{~nm}$ in length scale $(d=2 \pi / q)$, the intensity gain is about $70 \%$ for the nanocomposite. This correlates with the larger scale fibrillar structures observed for CNF-GO 0.07 in Fig. 4e and f. The SAXS signal from the GO shows a broad shoulder at about $1 \mathrm{~nm}^{-1}$, corresponding to a $d$-value of about $6 \mathrm{~nm}$. This can be explained by multi-layer stacks of GO. No such shoulder is present for the CNF-GO 0.07 sample, where the GO dispersion state is much better. The addition of GO to CNF results in formation of larger CNF entities, and improved in-plane CNF orientation.

In search for the origin of the larger fibrous structures in CNF-GO 0.07 nanopaper (see Fig. 4), the colloidal suspension of CNF-GO was freeze-dried and examined by FE-SEM. This may provide information on how CNFs and GO platelets were organized prior to filtration and de-watering. Fig. 7a and b shows long, thick CNF bundles with diameters as large as $6.9 \mu \mathrm{m}$. Since the TEMPO-CNF diameter is only $2-4 \mathrm{~nm}$, the large GO surface seems to promote the formation of thick, aligned CNF bundles, although care needs to be. Exercised in interpretation of freeze-dried structures. ${ }^{\mathbf{1 1 3}}$ GO may promote formation of

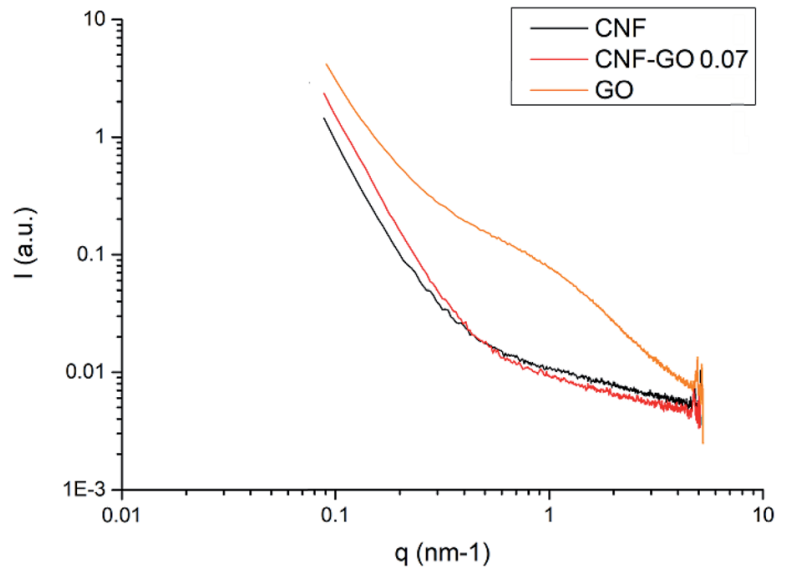

Fig. 6 Small angle $X$-ray scattering profiles (intensity (arbitrary units) versus scattering vector $q(q=(2 \pi / d)))$ of CNF, CNF-GO 0.07 vol\% and GO nanopaper films, where the $\mathrm{X}$-ray beam is perpendicular to the film plane.

thick CNF bundles, present as larger diameter CNF structures in the CNF-GO 0.07 micrographs in Fig. 4. A schematic sketch of how such an assembly process may take place is presented in Fig. 7c. Liquid flow during de-watering of the filtered gel may also promote local orientation and assembly of CNF fibrils.

\section{Barrier properties}

To further examine effects from GO content and differences in $\mathrm{CNF}$ organization, oxygen barrier properties were evaluated

Table 3 CNF orientation in neat CNF and CNF-GO 0.07 nanopaper films at three different $q$ ranges

\begin{tabular}{|c|c|c|c|}
\hline Sample & $\begin{array}{l}\text { Full width at half } \\
\text { maximum (FWHM) }\end{array}$ & $\begin{array}{l}\text { Degree of orientation } \\
\text { (П) }\end{array}$ & $\begin{array}{l}\text { Herman's orientation } \\
\text { factor }(f)\end{array}$ \\
\hline \multicolumn{4}{|c|}{$q=0.6-0.9 \mathrm{~nm}^{-1}$} \\
\hline Neat CNF & $25.2 \pm 0.1$ & $0.82 \pm 0.01$ & $0.91 \pm 0.01$ \\
\hline $\mathrm{CNF}-\mathrm{GO} 0.07$ & $14.2 \pm 0.2$ & $0.92 \pm 0.02$ & $0.93 \pm 0.01$ \\
\hline \multicolumn{4}{|l|}{$q=1-2 \mathrm{~nm}^{-1}$} \\
\hline Neat CNF & $43.2 \pm 0.1$ & $0.76 \pm 0.01$ & $0.86 \pm 0.01$ \\
\hline CNF-GO 0.07 & $24.2 \pm 0.1$ & $0.86 \pm 0.01$ & $0.91 \pm 0.01$ \\
\hline \multicolumn{4}{|c|}{$q=15-18 \mathrm{~nm}^{-1}$} \\
\hline Neat CNF & $36.4 \pm 0.1$ & $0.79 \pm 0.01$ & $0.89 \pm 0.01$ \\
\hline CNF-GO 0.07 & $31.5 \pm 0.1$ & $0.82 \pm 0.01$ & $0.90 \pm 0.01$ \\
\hline
\end{tabular}



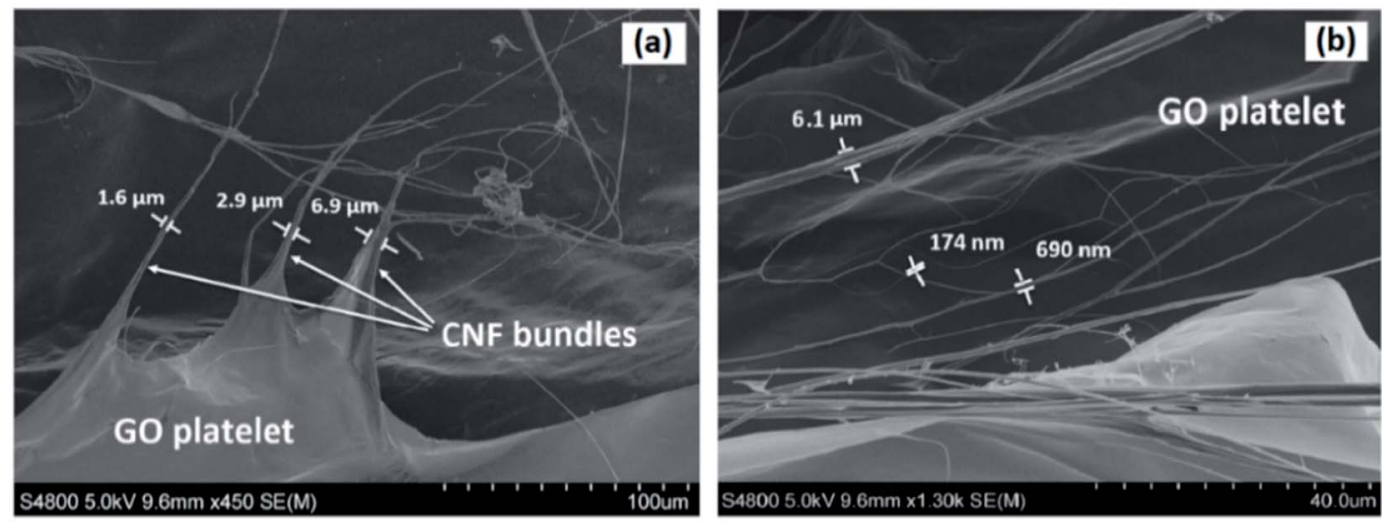

(c)

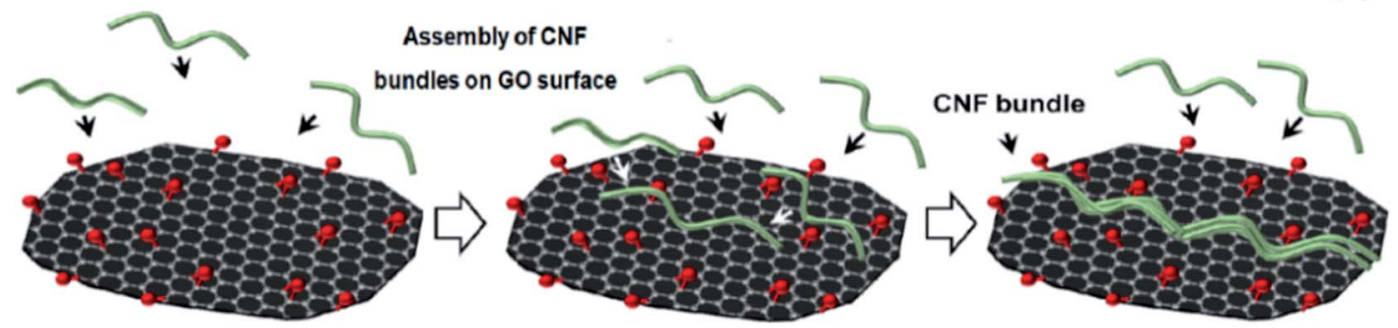

Fig. 7 FE-SEM images of freeze-dried CNF-GO 0.07 ( $a$ and b) and representation of suggested mechanism for assembly of CNF bundles on GO surface (c).

under humid conditions. This is important in packaging applications, where eco-friendly CNF films can function as barrier layers. ${ }^{41}$ The oxygen barrier properties of CNF films are known to be very good under ambient conditions. ${ }^{114}$ The oxygen permeability can even be below the detection limit for many instruments. In environments with a relative humidity significantly above $50 \%$ the situation is different, even for CNF composites with clay platelets. CNF fibrils adsorb moisture so that the film swells in the thickness direction and oxygen permeability is increased. ${ }^{30,55}$ In the present study, oxygen permeability tests were performed at $90 \%$ R.H. Since swelling and shrinkage due to changes in relative humidity are not necessarily reversible, the test was repeated using the same sample. This makes it possible to evaluate practically important reductions in barrier properties due to swelling and reorganization of the nanofibril network. Table 4 reports the results.

During the first test, all CNF and nanocomposite films show permeability values in the $0.4-0.5 \mathrm{~cm}^{3} \mathrm{~mm} \mathrm{~m}^{-2}$ day $^{-1} \mathrm{~atm}^{-1}$ range. These values are in the same range as data for polylactide
(PLA) coated by clay/polymer Layer-by-Layer (LbL) films, or commercial petroleum-based polymer laminates for gas barriers (e.g. PET/PVDC/PE). ${ }^{115,116}$ In Table 4, the oxygen permeability of the neat CNF film increased dramatically (14 times) after drying and re-exposure to $90 \% \mathrm{RH}$. The reason is changes in film structure, such as increased nanoporosity, so that film swelling is increased during the second exposure to $90 \% \mathrm{RH}$. One may note that the absolute oxygen permeability value for the neat CNF film is about $70 \%$ of the value reported in ref. 112 for a filtered, neat TEMPO CNF film.

CNF-GO nanocomposite films show completely different behavior than neat CNF films. The original barrier properties are preserved even after the second test, which means that GO has a stabilizing effect on the CNF network. For the higher GO contents ( 0.3 and $0.7 \mathrm{vol} \%)$ the permeability is even decreased after a drying and moisturizing cycle. The ordering of CNF in the presence of GO, as demonstrated by SAXS analysis and FESEM images, appears to prevent detrimental CNF rearrangement during humidity changes. This stabilization effect is

Table 4 Oxygen barrier properties of CNF-GO and pure CNF films at $90 \% \mathrm{RH}$ and room temperature $23^{\circ} \mathrm{C}$. Between the first and the second test, the specimens were dried to below $10 \% \mathrm{RH}$ and then again exposed to $90 \% \mathrm{RH}$ until steady state conditions were obtained. The experimental error is $\pm 5 \%$

\begin{tabular}{|c|c|c|}
\hline Sample & $\begin{array}{l}\text { Permeability first } \\
\text { test }\left[\mathrm{cm}^{3} \mathrm{~mm} \mathrm{~m}^{-2} \text { day }^{-1} \mathrm{~atm}^{-1}\right]\end{array}$ & $\begin{array}{l}\text { Permeability second } \\
\text { test }\left[\mathrm{cm}^{3} \mathrm{~mm} \mathrm{~m}^{-2} \text { day }^{-1} \mathrm{~atm}^{-1}\right]\end{array}$ \\
\hline $\mathrm{CNF}$ & 0.43 & 6.5 \\
\hline CNF-GO 0.07 & 0.40 & 0.51 \\
\hline CNF-GO 0.3 & 0.47 & 0.25 \\
\hline CNF-GO 0.7 & 0.40 & 0.27 \\
\hline
\end{tabular}


important in applications of $\mathrm{CNF} / \mathrm{GO}$ films and coatings, where RH is likely to vary during service. Furthermore, the possibility to use a single layer bio-based barrier film with improved moisture cycling resistance is attractive for replacement of multi-layer barriers. ${ }^{63}$

The reported barrier properties are superior to those reported for CNF/clay films, where exfoliated and oriented silicate platelets provide favorable barrier properties in humid conditions. The problem with such nanocomposites is that the oxygen barrier properties are not sufficient at low clay content. At high clay content, the optical transmittance, toughness, and strength of the film can be compromised. ${ }^{30,117}$ In the present case, CNF-GO nanocomposites with only $0.07-0.3$ vol\% of GO show excellent barrier properties and humidity cycling endurance with preserved or improved mechanical properties. The GO platelet component in CNF-GO films shows high reinforcement efficiency and also efficiency in maintaining barrier properties during moisture cycling enhancement. Chemical crosslinking of CNF fibrils may further improve moisture stability, ${ }^{118}$ but would compromise recycling potential.

\section{Conclusions}

Nanostructured biocomposites, based on low content of inplane oriented GO platelets of large size ( $2-40 \mu \mathrm{m}$ "diameter") in a matrix of random-in-plane CNF fibrils, were investigated. Despite very low GO content $(0.07 \mathrm{vol} \%)$, the absolute mechanical properties were very high as exemplified by $E=$ $17 \mathrm{GPa}$, yield strength $128 \mathrm{MPa}$ and an ultimate strength of $250 \mathrm{MPa}$. This is much higher than reported for GO composites with isotropic polymer matrices, and one reason is the favorable properties of the CNF matrix due to in-plane orientation of stiff and strong CNF nanofibrils. Since the GO content is low, the $\mathrm{CNF} / \mathrm{GO}$ nanocomposites also show high optical transmittance.

Interestingly, the modulus of the CNF film increased from 13.5 to $17.3 \mathrm{GPa}$ by addition of a "homeopathic" amount of only 0.07 vol\% GO; this effect cannot be explained by composite micromechanics theory for platelet reinforcement, since the GO content is simply too low. The main reason is in-plane CNF ordering and formation of CNF bundles in the presence of large size GO platelets. This increases the effective modulus of the CNF matrix in the composite, compared with the modulus for the neat CNF film, which is used in the theoretical prediction. Not only is the in-plane orientation increased due to the GO platelets, the GO also promotes the formation of thicker, more straight and oriented bundles of CNF. This explanation is supported by several sets of data: FE-SEM, SAXS, and WAXS. In addition, the GO induced nanostructural ordering of the CNF matrix contributed to strongly improved oxygen barrier properties at $90 \%$ relative humidity. The detrimental effect of repeated drying-moisturizing cycles was also strongly reduced in CNF-GO already at $0.07 \mathrm{vol} \%$ of $\mathrm{GO}$, with stronger improvement at higher GO contents; and this effect is related to the unique CNF organization and morphology.

The ordering effect on a TEMPO-CNF matrix from large GO platelets is important since strong effects are obtained at very small GO content, so that the optical transmittance remains high. Modulus reinforcement effects are superior to those reported for graphene-like reduced GO (RGO), despite lower GO platelet modulus, possibly because the present $\mathrm{GO}$ is better dispersed. The processing concept is eco-friendly and competitive with solvent-based or melt processing methods for petroleum-based polymer systems, since a hydrocolloidal mixture of CNF and GO is rapidly filtered and dried to form tough films. The high optical transmittance means that CNF/ GO can be used as a bio-based transparent coating with excellent mechanical and gas barrier properties.

\section{Conflicts of interest}

There are no conflicts to declare.

\section{Acknowledgements}

Wallenberg Wood Science Center is acknowledged for financial support and Asbury Carbons Inc for providing graphite flakes. Dr Lin Yang helped in X-ray scattering data reduction. The LiX beamline is part of the Life Science Biomedical Technology Research resource, jointly supported by the National Institute of Health, National Institute of General Medical Science under Grant P41GM111244, and by the Department of Energy Office of Biological and Environmental Research under Grant KP1605010, with additional support from NIH Grant S10OD012331. NSLS-II is a U.S. Department of Energy (DOE) Office of Science User Facility operated for the DOE office of Science by Brookhaven National Laboratory under contract no. DE-SC0012704. We also acknowledge Chalmers Areas of Advance and Dr Eric Tam for help with XPS analysis. Pan Chen acknowledges Beijing Municipal Natural Science Foundation (No. 2204096) and Beijing Institute of Technology Research Fund Program for Young Scholars. Hui Chen is acknowledged for optical transmittance measurements.

\section{References}

1 X. Huang, X. Qi, F. Boey and H. Zhang, Chem. Soc. Rev., 2012, 41, 666-686.

2 H. Kim, A. A. Abdala and C. Macosko, Macromolecules, 2010, 43, 6515-6530.

3 K. Hu, D. D. Kulkarni, I. Choi and V. V. Tsukruk, Prog. Polym. Sci., 2014, 39, 1934-1972.

4 M. Ahmadi, O. Zabihi, S. Jeon, M. Yoonessi, A. Dasari, S. Ramakrishna and M. Naebe, J. Mater. Chem. A, 2020, 8, 845-883.

5 Q. Wu, Y. Xu, Z. Yao, A. Liu and G. Shi, ACS Nano, 2010, 4, 1963-1970.

6 X. Zhou, T. Wu, B. Hu, G. Yang and B. Han, Chem. Commun., 2010, 46, 3663-3665.

7 J. Zhu, D. Yang, Z. Yin, Q. Yan and H. Zhang, Small, 2014, 10, 3480-3498.

8 K. Gao, Z. Shao, J. Li, X. Wang, X. Peng, W. Wang and F. Wang, J. Mater. Chem. A, 2013, 1, 63-67.

9 X. Li, R. Zhang, W. Yu, K. Wang, J. Wei, D. Wu, A. Cao, Z. Li, Y. Cheng and Q. Zheng, Sci. Rep., 2012, 2, 870. 
10 W. Yuan and G. Shi, J. Mater. Chem. A, 2013, 1, 1007810091.

11 Q. Liu, Z. Liu, X. Zhang, L. Yang, N. Zhang, G. Pan, S. Yin, Y. Chen and J. Wei, Adv. Funct. Mater., 2009, 19, 894-904.

12 S.-S. Li, K.-H. Tu, C.-C. Lin, C.-W. Chen and M. Chhowalla, ACS Nano, 2010, 4, 3169-3174.

13 S. Pang, Y. Hernandez, X. Feng and K. Müllen, Adv. Mater., 2011, 23, 2779-2795.

14 G. Eda and M. Chhowalla, Nano Lett., 2009, 9, 814-818.

15 G. Reina, J. M. González-Domínguez, A. Criado, E. Vázquez, A. Bianco and M. Prato, Chem. Soc. Rev., 2017, 46, 44004416.

16 S. Kumar and K. Chatterjee, ACS Appl. Mater. Interfaces, 2016, 8, 26431-26457.

17 G. Liu, W. Jin and N. Xu, Chem. Soc. Rev., 2015, 44, 50165030.

18 H. Li, Z. Song, X. Zhang, Y. Huang, S. Li, Y. Mao, H. J. Ploehn, Y. Bao and M. Yu, Science, 2013, 342, 95-98.

19 W.-L. Song, M.-S. Cao, M.-M. Lu, S. Bi, C.-Y. Wang, J. Liu, J. Yuan and L.-Z. Fan, Carbon, 2014, 66, 67-76.

20 Y. Xu, W. Hong, H. Bai, C. Li and G. Shi, Carbon, 2009, 47, 3538-3543.

21 C.-H. Chang, T.-C. Huang, C.-W. Peng, T.-C. Yeh, H.-I. Lu, W.-I. Hung, C.-J. Weng, T.-I. Yang and J.-M. Yeh, Carbon, 2012, 50, 5044-5051.

22 B. P. Singh, B. K. Jena, S. Bhattacharjee and L. Besra, Surf. Coating. Technol., 2013, 232, 475-481.

23 Y. Cui, S. Kundalwal and S. Kumar, Carbon, 2016, 98, 313333.

24 O. M. Istrate, K. R. Paton, U. Khan, A. O'Neill, A. P. Bell and J. N. Coleman, Carbon, 2014, 78, 243-249.

25 H. Kim and C. W. Macosko, Polymer, 2009, 50, 3797-3809.

26 M. F. Ashby, Materials and Sustainable Development, Butterworth-Heinemann, 2015.

27 S. J. Eichhorn, A. Dufresne, M. Aranguren, N. Marcovich, J. Capadona, S. Rowan, C. Weder, W. Thielemans, M. Roman and S. Renneckar, J. Mater. Sci., 2010, 45, 1-33.

28 D. Klemm, F. Kramer, S. Moritz, T. Lindström, M. Ankerfors, D. Gray and A. Dorris, Angew. Chem., Int. Ed., 2011, 50, 5438-5466.

29 H. Sehaqui, A. Liu, Q. Zhou and L. A. Berglund, Biomacromolecules, 2010, 11, 2195-2198.

30 A. Liu, A. Walther, O. Ikkala, L. Belova and L. A. Berglund, Biomacromolecules, 2011, 12, 633-641.

31 J. Fridman and S. Wulff, Forest Statistics 2019, Official Statistics of Sweden, Swedish University of Agricultural Sciences (SLU), Umeå, 2019, ISSN 0280-0543.

32 S. Kähkönen, E. Vakkilainen and T. Laukkanen, Energies, 2019, 12, 3689.

33 T. Saito, Y. Okita, T. Nge, J. Sugiyama and A. Isogai, Carbohydr. Polym., 2006, 65, 435-440.

34 X. Yang, M. S. Reid, P. Olsén and L. A. Berglund, ACS Nano, 2019, 14, 724-735.

35 S. Galland, F. Berthold, K. Prakobna and L. A. Berglund, Biomacromolecules, 2015, 16, 2427-2435.

36 A. Benítez and A. Walther, J. Mater. Chem. A, 2017, 5, 1600316024.
37 N. Mittal, F. Ansari, K. Gowda, V. C. Brouzet, P. Chen, P. T. Larsson, S. V. Roth, F. Lundell, L. Wagberg and N. A. Kotov, ACS Nano, 2018, 12, 6378-6388.

38 T. Saito, R. Kuramae, J. Wohlert, L. A. Berglund and A. Isogai, Biomacromolecules, 2013, 14, 248-253.

39 A. B. Fall, S. B. Lindström, O. Sundman, L. Ödberg and L. Wågberg, Langmuir, 2011, 27, 11332-11338.

40 U. Hirn and R. Schennach, Sci. Rep., 2015, 5, 1-9.

41 K. Syverud and P. Stenius, Cellulose, 2009, 16, 75.

42 N. D. Luong, N. Pahimanolis, U. Hippi, J. T. Korhonen, J. Ruokolainen, L.-S. Johansson, J.-D. Nam and J. Seppälä, J. Mater. Chem., 2011, 21, 13991-13998.

43 P. Das, J.-M. Malho, K. Rahimi, F. H. Schacher, B. Wang, D. E. Demco and A. Walther, Nat. Commun., 2015, 6, 1-14.

44 Z. Ling, C. E. Ren, M.-Q. Zhao, J. Yang, J. M. Giammarco, J. Qiu, M. W. Barsoum and Y. Gogotsi, Proc. Natl. Acad. Sci. U. S. A., 2014, 111, 16676-16681.

45 W. L. Song, P. Wang, L. Cao, A. Anderson, M. J. Meziani, A. J. Farr and Y. P. Sun, Angew. Chem., Int. Ed., 2012, 51, 6498-6501.

46 X. Wang, W. Xing, X. Feng, L. Song and Y. Hu, Polym. Rev., 2017, 57, 440-466.

47 R. M. Christensen, Mechanics of composite materials, Courier Corporation, 2012.

48 T. Huang, R. Lu, C. Su, H. Wang, Z. Guo, P. Liu, Z. Huang, H. Chen and T. Li, ACS Appl. Mater. Interfaces, 2012, 4, 26992708.

49 Z. Li, R. J. Young, N. R. Wilson, I. A. Kinloch, C. Vallés and Z. Li, Compos. Sci. Technol., 2016, 123, 125-133.

50 L. Chen, C. Xiao, Y. Tang, X. Zhang, K. Zheng and X. Tian, Ceram. Int., 2019, 45, 12965-12974.

51 M. Saeidijavash, J. Garg, B. Grady, B. Smith, Z. Li, R. J. Young, F. Tarannum and N. B. Bekri, Nanoscale, 2017, 9, 12867-12873.

52 P. Kumar, S. Yu, F. Shahzad, S. M. Hong, Y.-H. Kim and C. M. Koo, Carbon, 2016, 101, 120-128.

53 N. Yousefi, M. M. Gudarzi, Q. Zheng, X. Lin, X. Shen, J. Jia, F. Sharif and J.-K. Kim, Composites, Part A, 2013, 49, 42-50.

54 Y. Li, Z. Yang, H. Qiu, Y. Dai, Q. Zheng, J. Li and J. Yang, J. Mater. Chem. A, 2014, 2, 14139-14145.

55 C.-N. Wu, T. Saito, S. Fujisawa, H. Fukuzumi and A. Isogai, Biomacromolecules, 2012, 13, 1927-1932.

56 Z. Tang, N. A. Kotov, S. Magonov and B. Ozturk, Nat. Mater., 2003, 2, 413-418.

57 N. Song, D. Jiao, S. Cui, X. Hou, P. Ding and L. Shi, ACS Appl. Mater. Interfaces, 2017, 9, 2924-2932.

58 P. Liu, C. Zhu and A. P. Mathew, J. Hazard. Mater., 2019, 371, 484-493.

59 F. Ren, W. Tan, Q. Duan, Y. Jin, L. Pei, P. Ren and D. Yan, Carbohydr. Polym., 2019, 209, 310-319.

60 J.-Y. Wang, S.-Y. Yang, Y.-L. Huang, H.-W. Tien, W.-K. Chin and C.-C. M. Ma, J. Mater. Chem., 2011, 21, 13569-13575.

61 D. Li, M. B. Müller, S. Gilje, R. B. Kaner and G. G. Wallace, Nat. Nanotechnol., 2008, 3, 101.

62 H.-D. Huang, C.-Y. Liu, D. Li, Y.-H. Chen, G.-J. Zhong and Z.-M. Li, J. Mater. Chem. A, 2014, 2, 15853-15863. 
63 A. Khosravi, A. Fereidoon, M. M. Khorasani, G. Naderi, M. R. Ganjali, P. Zarrintaj, M. R. Saeb and T. J. Gutiérrez, Food Packaging Shelf Life, 2020, 23, 100429.

64 D. Zhang, J. Tong, B. Xia and Q. Xue, Sens. Actuators, B, 2014, 203, 263-270.

65 B. P. Singh, B. K. Jena, S. Bhattacharjee and L. Besra, Surf. Coat. Technol., 2013, 232, 475-481.

66 W. Peng, H. Li, Y. Liu and S. Song, J. Mol. Liq., 2017, 230, 496-504.

67 C. Zhang, R. Z. Zhang, Y. Q. Ma, W. B. Guan, X. L. Wu, X. Liu, H. Li, Y. L. Du and C. P. Pan, ACS Sustainable Chem. Eng., 2015, 3, 396-405.

68 L. Medina, Y. Nishiyama, K. Daicho, T. Saito, M. Yan and L. A. Berglund, Macromolecules, 2019, 52, 3131-3140.

69 Z. Hu, S. Wang, G. Chen, K. Wu, J. Shi, L. Liang and M. Lu, Compos. Sci. Technol., 2018, 168, 287-295.

70 Q. Li, Z. Xue, J. Zhao, C. Ao, X. Jia, T. Xia, Q. Wang, X. Deng, W. Zhang and C. Lu, Chem. Eng. J., 2020, 383, 123101.

71 R. K. Layek, K. R. Ramakrishnan, E. Sarlin, O. Orell, M. Kanerva, J. Vuorinen and M. Honkanen, J. Mater. Chem. A, 2018, 6, 13203-13214.

72 C.-J. Kim, W. Khan, D.-H. Kim, K.-S. Cho and S.-Y. Park, Carbohydr. Polym., 2011, 86, 903-909.

73 Q. Jiang, C. Kacica, T. Soundappan, K.-k. Liu, S. Tadepalli, P. Biswas and S. Singamaneni, J. Mater. Chem. A, 2017, 5, 13976-13982.

74 W. Yang, Z. Zhao, K. Wu, R. Huang, T. Liu, H. Jiang, F. Chen and Q. Fu, J. Mater. Chem. C, 2017, 5, 3748-3756.

75 P. Laaksonen, A. Walther, J. M. Malho, M. Kainlauri, O. Ikkala and M. B. Linder, Angew. Chem., Int. Ed., 2011, 50, 8688-8691.

76 C. Lee, X. Wei, J. W. Kysar and J. Hone, Science, 2008, 321, $385-388$.

77 L. N. Dang and J. Seppälä, Cellulose, 2015, 22, 1799-1812.

78 L. Gong, I. A. Kinloch, R. J. Young, I. Riaz, R. Jalil and K. S. Novoselov, Adv. Mater., 2010, 22, 2694-2697.

79 Q. Zheng, Y. Geng, S. Wang, Z. Li and J.-K. Kim, Carbon, 2010, 48, 4315-4322.

80 S. H. Aboutalebi, M. M. Gudarzi, Q. B. Zheng and J. K. Kim, Adv. Funct. Mater., 2011, 21, 2978-2988.

81 M. J. McAllister, J.-L. Li, D. H. Adamson, H. C. Schniepp, A. A. Abdala, J. Liu, M. Herrera-Alonso, D. L. Milius, R. Car and R. K. Prud'homme, Chem. Mater., 2007, 19, 4396-4404.

82 D. C. Marcano, D. V. Kosynkin, J. M. Berlin, A. Sinitskii, Z. Sun, A. Slesarev, L. B. Alemany, W. Lu and J. M. Tour, ACS Nano, 2010, 4, 4806-4814.

83 P. Cui, J. Lee, E. Hwang and H. Lee, Chem. Commun., 2011, 47, 12370-12372.

84 A. C. Ferrari and D. M. Basko, Nat. Nanotechnol., 2013, 8, 235.

85 A. M. Dimiev and S. Eigler, Graphene oxide: fundamentals and applications, John Wiley \& Sons, 2016.

86 G. Wang, X. Shen, B. Wang, J. Yao and J. Park, Carbon, 2009, 47, 1359-1364.

87 Y. Xu, Z. Liu, X. Zhang, Y. Wang, J. Tian, Y. Huang, Y. Ma, X. Zhang and Y. Chen, Adv. Mater., 2009, 21, 1275-1279.
88 D. Swinehart, J. Chem. Educ., 1962, 39, 333.

89 M.-C. Hsieh, H. Koga, K. Suganuma and M. Nogi, Sci. Rep., 2017, 7, 1-7.

90 R. R. Nair, P. Blake, A. N. Grigorenko, K. S. Novoselov, T. J. Booth, T. Stauber, N. M. Peres and A. K. Geim, Science, 2008, 320, 1308-1308.

91 M. Pääkkö, M. Ankerfors, H. Kosonen, A. Nykänen, S. Ahola, M. Österberg, J. Ruokolainen, J. Laine, P. T. Larsson and O. Ikkala, Biomacromolecules, 2007, 8, 1934-1941.

92 R. J. Crawford, K. J. Edler, S. Lindhoud, J. L. Scott and G. Unali, Green Chem., 2012, 14, 300-303.

93 R. Tanaka, T. Saito, H. Hondo and A. Isogai, Biomacromolecules, 2015, 16, 2127-2131.

94 J.-M. Malho, P. i. Laaksonen, A. Walther, O. Ikkala and M. B. Linder, Biomacromolecules, 2012, 13, 1093-1099.

95 K. Gao, Z. Shao, X. Wu, X. Wang, J. Li, Y. Zhang, W. Wang and F. Wang, Carbohydr. Polym., 2013, 97, 243-251.

96 C. Xu, G. Wang, C. Xing, L. M. Matuana and H. Zhou, BioResources, 2015, 10, 2809-2822.

97 Y. Beeran, V. Bobnar, S. Gorgieva, Y. Grohens, M. Finšgar, S. Thomas and V. Kokol, RSC Adv., 2016, 6, 49138-49149.

98 J. Duan, S. Gong, Y. Gao, X. Xie, L. Jiang and Q. Cheng, ACS Appl. Mater. Interfaces, 2016, 8, 10545-10550.

99 N. Song, D. Jiao, P. Ding, S. Cui, S. Tang and L. Shi, J. Mater. Chem. C, 2016, 4, 305-314.

100 W. Yang, Y. Zhang, T. Liu, R. Huang, S. Chai, F. Chen and Q. Fu, ACS Sustainable Chem. Eng., 2017, 5, 9102-9113.

101 N. Song, S. Cui, D. Jiao, X. Hou, P. Ding and L. Shi, Carbon, 2017, 115, 338-346.

102 L. Li, B. Zhou, G. Han, Y. Feng, C. He, F. Su, J. Ma and C. Liu, Compos. Sci. Technol., 2020, 108229.

103 S. Tanpichai, F. Quero, M. Nogi, H. Yano, R. J. Young, T. Lindström, W. W. Sampson and S. J. Eichhorn, Biomacromolecules, 2012, 13, 1340-1349.

104 O. Blakslee, D. Proctor, E. Seldin, G. Spence and T. Weng, J. Appl. Phys., 1970, 41, 3373-3382.

105 J. W. Suk, R. D. Piner, J. An and R. S. Ruoff, ACS Nano, 2010, 4, 6557-6564.

106 C. Gómez-Navarro, M. Burghard and K. Kern, Nano Lett., 2008, 8, 2045-2049.

107 Y. Gao, L.-Q. Liu, S.-Z. Zu, K. Peng, D. Zhou, B.-H. Han and Z. Zhang, ACS Nano, 2011, 5, 2134-2141.

108 A. J. Benítez and A. Walther, Biomacromolecules, 2017, 18, 1642-1653.

109 Y. Kojima, A. Usuki, M. Kawasumi, A. Okada, Y. Fukushima, T. Kurauchi and O. Kamigaito, J. Mater. Res., 1993, 8, 1185-1189.

110 A. Pei, Q. Zhou and L. A. Berglund, Compos. Sci. Technol., 2010, 70, 815-821.

111 H. Soeta, S. Fujisawa, T. Saito, L. Berglund and A. Isogai, ACS Appl. Mater. Interfaces, 2015, 7, 11041-11046.

112 M. Zhao, F. Ansari, M. Takeuchi, M. Shimizu, T. Saito, L. Berglund and A. Isogai, Nanoscale Horiz., 2018, 3, 28-34.

113 F. Jiang and Y.-L. Hsieh, ACS Sustainable Chem. Eng., 2016, 4, 1041-1049. 
114 H. Fukuzumi, T. Saito, S. Iwamoto, Y. Kumamoto, T. Ohdaira, R. Suzuki and A. Isogai, Biomacromolecules, 2011, 12, 4057-4062.

115 F. Carosio, S. Colonna, A. Fina, G. Rydzek, J. Hemmerlé, L. Jierry, P. Schaaf and F. Boulmedais, Chem. Mater., 2014, 26, 5459-5466.
116 J. Lange and Y. Wyser, Packag. Technol. Sci., 2003, 16, 149158.

117 J. Wang, D. J. Gardner, N. M. Stark, D. W. Bousfield, M. Tajvidi and Z. Cai, ACS Sustainable Chem. Eng., 2017, 6, 49-70.

118 L. Liang, S. Bhagia, M. Li, C. Huang and A. J. Ragauskas, ChemSusChem, 2020, 13, 78-87. 